\title{
TO WORK WITH GIFTED CHILDREN IN THE SYSTEM OF INFORMAL EDUCATION IN PR CHINA: TRAINING OF SPORTS`DISCIPLINES`TEACHERS
}

\section{Wu Yanlin ${ }^{1}$ \\ Mkrtichian Oksana ${ }^{2}$}

DOI: https://doi.org/10.30525/978-9934-571-89-3_25

The basic principle of the educational systems of developed countries functioning is the involvement of a citizen in continuous, lifelong learning. A leading form of implementation of this principle and public demand is the provision of educational services in the informal sector, or non-formal education. PR China is now undergoing

${ }^{1}$ H.S. Skovoroda Kharkiv National Pedagogical University, Ukraine

${ }^{2}$ Kharkiv National University of Economics named after Semen Kuznets, Ukraine 
the formation of the education system mentioned. And the Chinese system of informal education itself is the main user of the abroad teacher's resource, since it is exactly the work of the institutions of non-formal education of the People's Republic of China that invites a large number of teachers and other pedagogical workers from other countries.

For a long period of time formal education was considered to be traditional and generally accepted form of acquiring knowledge and skills, which was widely adopted both in the Western countries and in China. The definition of non-formal education that is traditional for European science is as following: any kind of organized and systematic activity that may not coincide with the activities of schools, colleges, universities and other institutions that are part of the formal education system. In the social sciences and in the practice of modern pedagogy, the term is used along with the concepts of "continuous education", "additional education" and "self-education" to describe the realities of the modern world, where the process of mastering new knowledge and skills accompanies an individual throughout life, taking various forms. As a rule, non-formal education is considered in opposition to formal education, which takes place within the framework of official educational institutions and is accompanied by the obtaining of officially recognized educational documents. Non-formal education also plays an important role in educating children and adults who cannot attend school, or the school education does not fulfill their needs [1, p. 18].

As to the People's Republic of China, today the interpretation of the concept of "non-formal education" in this country proceeds from its main functions: to serve as a source of minimal and obligatory knowledge and qualifications' gaining for people who, due to their lifestyle and remoteness from urban centers, do not have the opportunity to attend educational institutions of the formal education system, as well as being a source of additional knowledge, skills and qualifications for those who receive education in public kindergartens, schools, universities etc. Also, unlike other countries, the issuance of a diploma or certificate is mandatory for non-formal education institutions in the PR China [2, p. 14].

Today, various forms of non-formal education exist in the system of pre-school, school, professional and higher education of China. In the People's Republic of China sporting development groups, dancing clubs, Chinese history, drawing, English, etc., created by the initiatives of local self-government for the elderly people are also very popular. A peculiar "boom" of informal education was initiated by the state in 20062007 in the framework of preparations for the Olympics: free clubs and clubs for studying the standards of etiquette, English language, history and culture of China, rules for communication with foreigners, etc. were opened everywhere. Today, the average child age 5-10 years old living in the city attends from 2 to 5 additional circles. The most popular sections are wushu, dancing, drawing, English (mainly at school, which was opened or taught by foreigners), "schools of young ladies and gentlemen", etc [3, p. 12].

Today, the institutions of non-formal education play a major role in the system of profile selection of potentially sports-gifted children. Since the fact that the child 
additionally engaged in a sports section is prestigious for parents and family, it forms a large number of children going in for sports. Their coaches and sports teachers (when it comes to private schools that are called to take a child after classes and that are gaining popularity in big cities), they can carry out an initial selection of talented and sports-gifted children. As a rule, coaches and teachers work in close cooperation with junior local, municipal and national teams, representatives of state educational institutions for sports-gifted children who regularly attend trainings and competitions held in the field of informal education as a means of assessing the qualifications of teachers and trainers (the sector of non-formal education is traditionally considered a "staffing reserve" for formal education in China), as well as the search for talented and gifted children. Then children have the opportunity to get to the institutions of the state system of work with gifted youth (specialized schools, boarding schools, etc.).

Each country solves the problem of a qualified corps of teachers` training, including teachers of sports disciplines, based on its own pedagogical traditions and theoretical and methodological approaches. In the PR China, there is no deliberate training of future teachers of sports disciplines to work in institutions of non-formal education. It is believed that at the university students are to master the complex of universal knowledge, skills and abilities, and their practical adaptation and profiling they will gain at the first place of work. Therefore, the system of informal education in China is used by future teachers of sports disciplines as a kind of "platform for practice", where there is an opportunity to take a social practice in free time and gain practical experience. The stimulation and self-promotion of the Chinese studentsfuture teachers of sports disciplines and trainers for inclusion in the informal segment of education is an important aspect of its qualitative improvement. The most important argument in favor of such participation for students in the PR China is not the pursuit of deep learning of a certain type of knowledge and skills, but a pragmatic and realistic goal: to increase their own competitiveness even while studying and create a presentable portfolio for the future employer.

\section{References:}

1. Billets T. (2011). Critiquing workplace learning discourses: participation and continuity at work. Studies in the Education of Adults, 34(1), p. 17-31.

2. Chen T. (2016). Comparison of the characteristics of formal and informal education. Bulletin of the Nankin Pedagogical University, 3, p. 2-16. (in Chinese).

3. Zhang M. (2000). Scientific understanding of status and role of informal and additional education. Chinese Academic Journal of Education, no. 3, p. 11-15. (in Chinese) 